\title{
Adrenal Cortex
}

National Cancer Institute

\section{Source}

National Cancer Institute. Adrenal Cortex. NCI Thesaurus. Code C12396.

The outer region of the adrenal gland consisting of the zona glomerulosa, the zona fasciculata, and the zona reticularis. The adrenal cortex produces and secretes mineralocorticoids, glucocorticoids, and adrenal androgens. 